ECCOMAS

Proceedia
EUROGEN 2021

$14^{\text {th }}$ ECCOMAS Thematic Conference on Evolutionary and Deterministic Methods for Design, Optimization and Control

N. Gauger, K. Giannakoglou, M. Papadrakakis, J. Periaux (eds.) Streamed from Athens, Greece, 28-30 June 2021

\title{
OPTIMUM DESIGN OF TUNED MASS DAMPERS FOR REAL-SIZE STRUCTURES VIA ADAPTIVE HARMONY SEARCH ALGORITHM
}

\author{
Aylin Ece Kayabekir ${ }^{1}$, Sinan Melih Nigdeli ${ }^{1}$, Gebrail Bekdaş ${ }^{1}$, and Melda Yücel ${ }^{1}$ \\ ${ }^{1}$ Department of Civil Engineering, Istanbul University - Cerrahpaşa \\ Avcilar, Istanbul, Turkey \\ e-mail: ecekayabekir@gmail.com,melihnig@istanbul.edu.tr, \\ bekdas@istanbul.edu.tr, melda.yucel@yahoo.com.tr
}

\begin{abstract}
In control of structures for earthquake excitation, tuned mass dampers (TMDs) can be used. For the efficiency of a passive control system, it is needed to tune the parameters of TMD according to the parameters of the structures. For this aim, the use of metaheuristic methods plays an important role in the optimization of TMDs. Metaheuristic algorithms are inspired by a process of a happening or a living creature. Harmony Search (HS) imitates the musical performance process involving the note tuning process of musicians to gain the admiration of audiences. In the algorithm, two types of optimization using global and local searches are used. In global, a new note is generated, while a neighboring value is assigned in local search as the imitation of playing something similar to the known notes. In this process, two algorithm-specific parameters are used. These parameters are called harmony memory considering rate (HMCR) and pitch adjusting rate (PAR). The chosen values of parameters may be effective on the performance of the algorithm. For that reason, adaptive techniques that automatically update the parameter in the iterations are also suggested. In the present study, adaptive HS is presented on optimum design of TMD for structures subjected to earthquake excitations. For the numerical examinations, a real-size structure plan is considered by checking the stroke capacity of TMD during optimization. Also, the optimization is done by using a wide set of earthquake records to find a general solution. According to the results, the adaptive HS is very suitable to find a feasible TMD for structures subjected to earthquake excitations.
\end{abstract}

Keywords: Structural Control, Tuned Mass Dampers, Optimization, Metaheuristic Algorithms, Harmony Search 


\section{INTRODUCTION}

Safe design and modeling of the structures is a significant issue in the meaning of safety against structural hazards or collapses for these structures, which are subjected to dynamic excitations such as earthquake, wind, wave, etc. In this regard, these dangers can be prevented by absorbing the energy of mentioned excitations through the usage of some devices as structural control systems. The mentioned devices contain several options known as passive, active, semi-active, and hybrid systems.

Passive control systems, which are more widely used ones, have various applications such as diagonal steel bracing, seismic base isolation, tuned mass or liquid dampers. These systems are more economic, and comfortable to apply according to other ones, but there is a disadvantage intended for near-fault ground motions, which have high-level peak velocities. On the other side, active systems provide the limitation of structural responses (displacement, velocity or acceleration) produced by dynamic excitations like earthquakes through benefiting from an energy source placed within the structure. Also, these devices contain several types such as active mass damper, active tendon systems, active variable stiffness systems, etc. The semiactive structural control system is created with the usage of both passive and active ones. These systems provide more structural protection across passive systems, but damping of responses realizes in lower level than active systems. As to hybrid systems, they are also modeled similar to semi-active systems. They can be also utilized during an earthquake even if power cuttings thanks to having a passive control part.

It is one of the most-used devices from structural passive control systems, that tuned mass damper (TMD) provides the reducing and then stopping of responses namely vibrations within any structures under dynamic effects. Optimum tuning of the mechanical parameters of the device is the most important issue to realize the mentioned aims by these systems. These parameters are comprised of frequency and damping factors of TMD's, which are substantially related to natural period or damping ratio of structure. Also, for active systems, optimum tuning of controller parameters is required for providing sufficient protection. Furthermore, excitation character is also a significant factor in the meaning of efficiency and performance of optimum TMD design. Apart from these, these devices can be benefited within numerous structures such as automobiles, trains, airplanes, construction equipment, etc. to balance vibrations. As to traditional constructions, so many applications are made for old/new-built structures containing skyscrapers, television towers, pedestrian or highway bridges, stadiums, nuclear plants, etc. to keep safety level by absorbing vibrations produced by seismic activations as earthquake besides wind forces, traffic movements or noises, too.

The origin of the mentioned vibration absorption device as TMDs is based on the invention of Frahm [1] that is a simple version of TMDs and contains one mass, which has also a stiffness member like spring. Following, the second progression is realized by Ormondroyd and Den Hartog [2]. They updated the first version of TMDs by placing a damping part to classical form, and thanks to this development, vibrations occurred by random frequency excitations came to reducible and absorbable.

In addition to these, the most popular usage for TMDs belongs to Taipei 101 skyscraper building located in Taiwan. Here, TMD has a formation with a huge spherical mass connected with cables (stiffness elements) together with hydraulic pumps (damping members), and this vibrator-like pendulum ensures decreasing strong wind effects, besides earthquake effects, too. Moreover, a TMD for the Berlin television tower in Germany was established to protect the structure toward powerful wind forces. As a different application in the use of TMDs, retrofitting of existing/old structures was carried out to protect against seismic effects. For example, Lax Theme Building in International Los Angeles Airport was restored via TMD, which is 
designed similar to a slab containing several viscous dampers and base isolation systems. Thanks to this application, it was observed that structural responses can be decreased up to $40 \%[3]$.

These control devices can be utilized for structures with single (SDOF) and also multiple (MDOF) degrees of freedom. In SDOF structures, the basic purpose of the usage of TMDs is to generate a secondary mode, which is slightly close to the frequency level of the main structure. In that case, it prevents the generation of any resonance. Furthermore, the motion of TMDs during any vibration case can be controlled and tuned due to TMDs having damping capability. Here, this expression is based on the damping parameter of TMDs, and it should be determined as suitable as possible namely optimum. Besides, there are also some important properties for optimum controlling of TMD's such as stiffness, frequency or mass, etc. To make it possible to find these parameter values, different formulations or equations were developed, but none of them contains a definite solution due to that structures may be under excitations with random frequencies. As an example to proposed formulations from previous literature, Den Hartog developed two separate expressions based on the determination of a parameter, which is the ratio of frequencies belonging to the undamped main structure and TMD system, besides the optimum ratio of damping [4]. However, in various applications, these expressions are investigated by dealing with inherent damping for SDOF structure, too [5-6]. Following, by Warburton, different formulations were suggested for various loadings such as random white noise and harmonic excitations as regards undamped SDOF structures again [7]. On the other side, Sadek et al. produced some formulas by operating numerical methods for SDOF and MDOF main systems, which have inherent damping [8]. These formulas also play a part in the scope of reduction of structural responses such as displacement and acceleration that occurred under different earthquake excitations.

However, metaheuristic-algorithms, which can be utilized as estimation or optimization methods, besides, advanced computing approaches, numerical calculating, and analysis techniques can help to evaluate whole vibration modes in MDOF structures. In this meaning, some studies and applications were realized with the mentioned metaheuristic approaches, which were designed by inspiring from properties of alives within natural life, physical or chemical processes, capabilities based on memory, etc.

For example, the starting of metaheuristic methods, genetic algorithm (GA) was handled for the generation of optimum TMD design for structures with different types [9-13]. Also, particle swarm optimization (PSO), which can be assumed as the second step for metaheuristics, was investigated to find the optimal TMD parameters for viscously damped SDOF main systems exposed to different dynamic effects containing harmonic base acceleration, nonstationary or random Gaussian white noise excitations [14-15]. Various metaheuristic algorithms are also utilized for the generation of TMD design optimally intended for different targets or different structural types. These are comprised from the studies applied with ant colony optimization (ACO) [16], harmony search (HS) [17-20, 25], artificial bee colony algorithm (ABC) [21], gravitational search algorithm (GSA) [22], cuckoo search (CS) [23], bat algorithm (BA) [24], teaching-learning-based optimization (TLBO) [19-20, 27], flower pollination algorithm (FPA) [19-20, 25-26, 28] and Jaya algorithm (JA) [20].

In the present study, the adaptive HS algorithm was presented for optimum design of TMDs that are positioned on the top of the structure subjected to earthquakes. The methodology is a multi-objective one that controls the stroke of the TMD in an applicable range limited by a user-defined value and minimization of the maximum top story displacement under a set of earthquake records. The method is presented on a 15 story real-size reinforced concrete $(\mathrm{RC})$ structure. 


\section{THE OPTIMIZATION METHODOLOGY AND ADAPTIVE HARMONY SEARCH}

Musician as an artist tries to generate any musical work with many efforts during long times. There are some points thought as remarkable, for instance, age, point of view, country or area where he lives, and also characteristic features, etc., while an artist is performing this action. On the other side, this musical work is revealed with the development of tunes or harmonies through examining and well combination of different note options. Here, the main purpose is to win the favor of listeners', and following he/she tries to develop the work by evaluating feedbacks. In this regard, this development process for any musical work can be assumed as an optimization case. Thus, in the year 2001, Geem et al. inspired by the mentioned process and proposed an optimization algorithm called harmony search (HS), which is one of the memory and musical-based metaheuristic methods [29]. As in many metaheuristic algorithms, some stages are also performed with HS for any optimization problem.

In this study, a modified version of HS is presented for the optimization problem. This modification includes an adaptive parameter setting and consideration of the best existing solution.

The optimization methodology as similar to all engineering optimization problems starts with the definition of the problem by the design constants, ranges and algorithm parameters. In the present study, it is also needed to define earthquake records for the dynamic analysis. In the study, a set of earthquake records are used and the excitation with the most effect is considered. The set is the records grouped as far-field ground motion records in FEMA P-695: Quantification of Building Seismic Performance Factors [30]. The design constants include the mass, stiffness and damping values of the structure. The design variables of the problem are the period $\left(\mathrm{T}_{\mathrm{d}}\right)$ and damping ratio $\left(\xi_{\mathrm{d}}\right)$ of TMD that is positioned on the structure. As a logical range, $\xi_{\mathrm{d}}$ is defined between 0.01 and 0.3 , while $\mathrm{T}_{\mathrm{d}}$ is searched between 0.5 and 1.5 times of the critical period of the structure.

The beginning stage is comprised of generation initial solutions (including 10 sets of design variables in the numerical example) following the definition of design variables, constants, and also parameters specific to the algorithm. The mentioned special parameters are known as harmony memory consideration rate (HMCR) and fret width (FW) that provide the renew of solutions with the controlling of musical memory and adjusting of tunes. However, these parameters are utilized in the second stage, which is the iteration process, namely, the fundamental updating application is carried out at this time.

For all generated candidate solutions, the objective function is calculated. These results are found via dynamic analysis. For this analysis, a program was developed via MATLAB with Simulink [31].

In the study, two objectives are considered. As given in Eqs. (1) and (2), the objectives; $f_{1}$ and $f_{2}$ are related with the maximum top story displacement $\left(\mathrm{x}_{\mathrm{N}}\right)$ and the stroke capacity of TMD. $f_{1}$ is minimized and $f_{2}$ must be lower than a user-defined value that is taken as 2 in the present study. $\mathrm{x}_{\mathrm{d}}$ is the displacement of TMD with respect to the ground.

Then the iteration process starts and it is done for several iterations (200 in the numerical example). All results corresponding candidate solutions are checked according to the following procedure. First, $f_{2}$ values are checked to minimize if both new and existing solutions exceed the limit taken as 2 . If one of them is smaller than 2 , it is taken as the best. If both $\mathrm{f}_{2}$ values are lower than $2, \mathrm{f}_{1}$ is considered in the optimization. 


$$
\mathrm{f}_{2}=\frac{\mathrm{f}_{1}=\max \left(\left|\mathrm{x}_{\mathrm{N}}\right|\right)}{\max \left(\left|\mathrm{x}_{\mathrm{d}}-\mathrm{x}_{\mathrm{N}}\right|\right)_{\text {with TMD }}}<2
$$

The iteration process is realized by choosing between two different alternatives as generating notes randomly (Eq. (3)) or playing from a specific fret through remembering of notes within memory (Eq. (4)). These are determined according to HMCR value compared with a number, which is a random value between 0 and 1 ( $\operatorname{rand}())$. Equations expressed the updating action for a new solution can be seen in Eqs. (3)-(4).

$$
\begin{gathered}
\text { if } \mathrm{HMCR}>\operatorname{rand}(), \quad \mathrm{X}_{\mathrm{i}, \text { new }}=\mathrm{X}_{\mathrm{i}, \min }+\operatorname{rand}()\left(\mathrm{X}_{\mathrm{i}, \max }-\mathrm{X}_{\mathrm{i}, \min }\right) \\
\text { if } \mathrm{HMCR}<\operatorname{rand}(), \quad \mathrm{X}_{\mathrm{i}, \text { new }}=\mathrm{X}_{\mathrm{i}, \mathrm{n}}+\operatorname{rand}\left(\frac{-1}{2}, \frac{1}{2}\right) \mathrm{FW}\left(\mathrm{X}_{\mathrm{i}, \max }-\mathrm{X}_{\mathrm{i}, \text { min }}\right)
\end{gathered}
$$

Where, for $\mathrm{i}^{\text {th }}$ design parameter, $\mathrm{X}_{\mathrm{i} \text {,new }}$ is new/updated value of solutions placed in matrix; $\mathrm{X}_{\mathrm{i}, \min }$ and $\mathrm{X}_{\mathrm{i} \text {,max }}$ are limits as lower and upper values of the dealed solution, besides $\mathrm{X}_{\mathrm{i}, \mathrm{n}}$ is $\mathrm{n}^{\text {th }}$ solution selected from initial matrix randomly.

Furthermore, in the current study, an adaptive version of HS is proposed with respect to the usage for optimum design of TMDs in the direction of determining the best mechanical properties of it. Also, this modification is called adaptive harmony search (AHS).

To realize this process, values of HMCR and FW parameters are adjusted and modified along with iterations according to pre-defined initial values $(0.5$ for both in the numerical example) of them and the current iteration step. For this reason, parameters are transformed to the new case as seen below equations.

$$
\begin{gathered}
\mathrm{FW}=\mathrm{FW}_{\text {in }}\left(1-\frac{\mathrm{IN}}{\mathrm{MI}}\right) \\
\mathrm{HMCR}=\mathrm{HMCR}_{\text {in }}\left(1-\frac{\mathrm{IN}}{\mathrm{MI}}\right)
\end{gathered}
$$

Here, the total iteration number is indicated with MI, besides IN is the current iteration step. Besides, $\mathrm{FW}_{\text {in }}$ and $\mathrm{HMCR}_{\text {in }}$ are meant to the constant values determined in the initial phase of the design process. Also, this operation provides to increase in remembering possibility for notes within memory progressively, and searching size is decreased due to that multiplier importance of limitation range goes to a smaller level. On the other side, there is another modification, which is benefited for the development of this version. This action is related to the selection of a solution, which will be considered and evaluated to use in updating. Here, this solution can be selected randomly among all solutions, or the determined as best one. This case is realized according to a value specified as the consideration rate of the best solution (BSCR) taken as 0.3 in the present study. In this respect, nth solution $\left(\mathrm{X}_{\mathrm{i}, \mathrm{n}}\right)$ seen in Eq. (4) is changed with the best one, when the randomly determined number is bigger than the value of this parameter, similar to HMCR.

\section{NUMERICAL EXAMPLE}

A case of a 3D structure is presented to verify the method on real-size buildings. 15-story reinforced concrete structure with the story plan given as Figure 1 is controlled with a TMD. The damping of the main structure was taken according to Rayleigh damping and it is assumed as 5\% for reinforced concrete structures. 


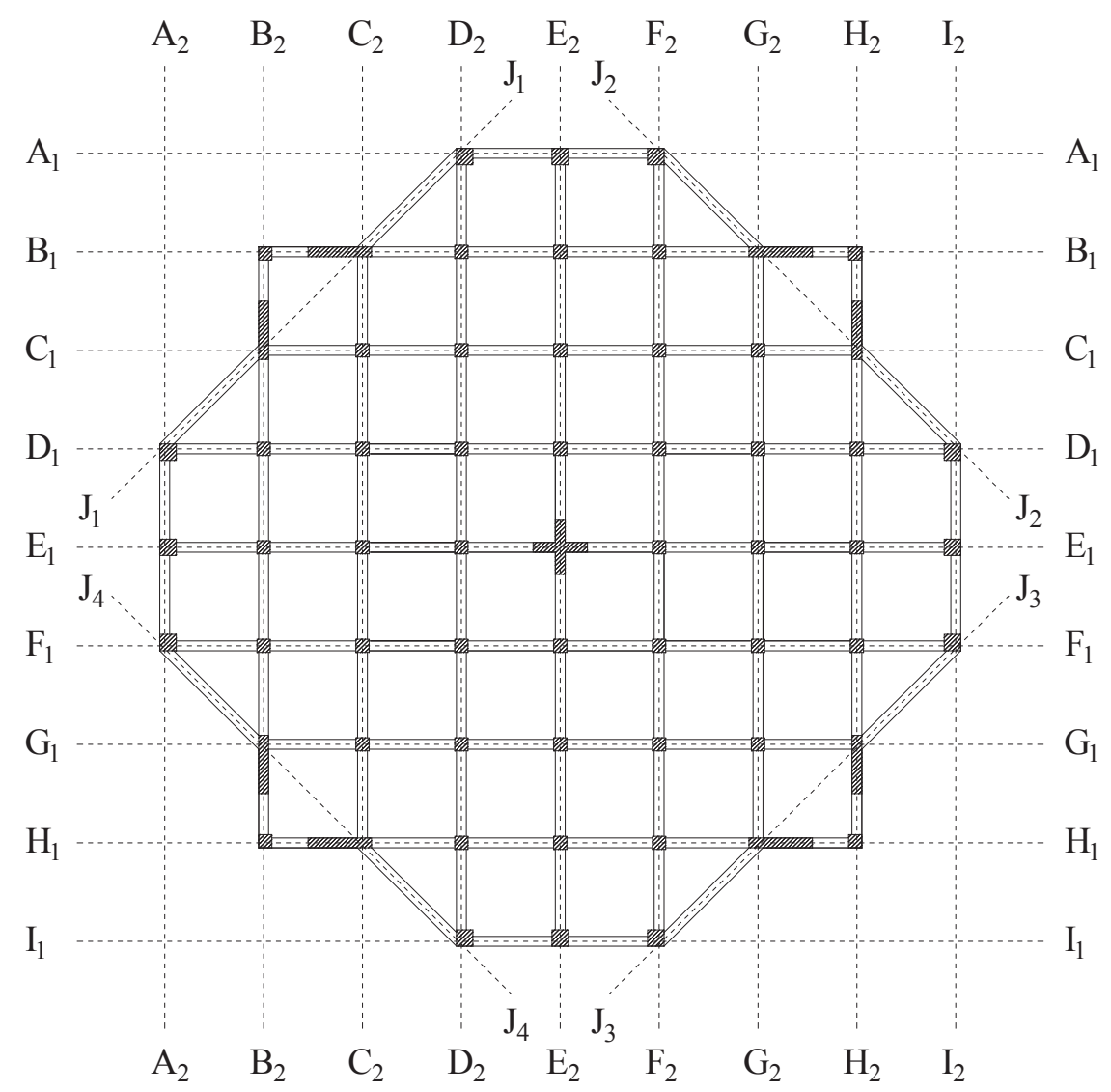

Figure 1: The story plan of reinforced concrete structure.

The 3D structure has 9 gridlines with equal distances between them in both directions. The distance between is $8 \mathrm{~m}$ and the height of each story is $3.5 \mathrm{~m}$. The rigidity of the structure in both translational directions was calculated as $5520 \mathrm{MN} / \mathrm{m}$. The structure has a 3590 -ton story mass.

The mass of TMD is taken as $2 \%$ of the total mass of the structure. The value of it is 1077 tons. The optimum values such as $\mathrm{T}_{\mathrm{d}}$ and $\xi_{\mathrm{d}}$ are found as 1.6770 and 0.1644 , respectively. The value of $f_{1}$ and $f_{2}$ for the optimum results are $0.3928 \mathrm{~m}$ and 1.9991 , respectively. The maximum displacement under a set of earthquake records is between $0.0425 \mathrm{~m}$ and $0.4638 \mathrm{~m}$ for the uncontrolled structure. For the structure with optimum TMD, the maximum displacement is changed between $0.0381 \mathrm{~m}$ and $0.3928 \mathrm{~m}$. The most critical excitation is the MUL009 component of the 1994 Northridge earthquake. The time-history plot for the top story displacement is shown in Figure 2.

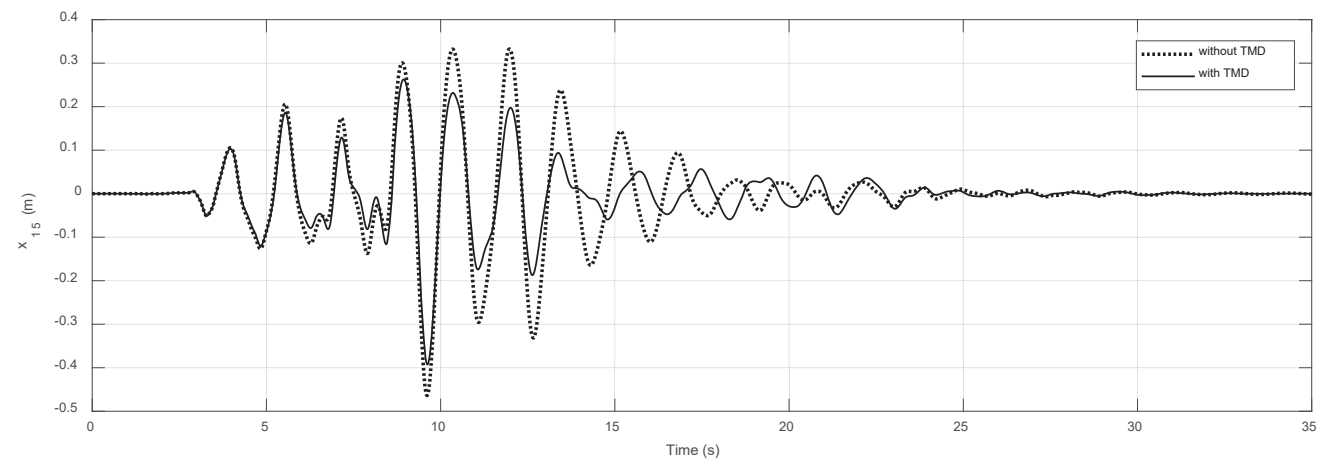

Figure 2: Time-history plot for the critical excitation. 


\section{CONCLUSIONS}

The aim of this study is to both present applications of a TMD on a real-size structure and an improved metaheuristic method for this application. According to the results, the optimization is effective and it can be seen from the reduction of the objective function values by $15.3 \%$. As seen from the time-history plot given for the most critical excitation, TMD is also effective on rapid damping and the effect of TMD is significant on the peak vibration with the most amplitude, but the essential effect is observed in the following peaks. Additionally, TMD is effective for all excitations that were used in the optimization.

\section{REFERENCES}

[1] H. Frahm, Device for damping of bodies. Washington, DC: U.S. Patent No: 989,958, 1911.

[2] J. Ormondroyd, J.P. Den Hartog, The theory of dynamic vibration absorber, Transactions of the ASME, 50, 922, 1928.

[3] H.K. Miyamoto, A.S.J. Gilani, Y.Z. Gündoğdu, Innovative seismic retroit of an iconic building. Seventh National Conference on Earthquake Engineering, Istanbul, Turkey, May 30-June 3, 2011.

[4] J.P. Den Hartog, Mechanical vibrations. McGraw-Hill, New York, 1947.

[5] R.E.D. Bishop, D.B. Welbourn, The problem of the dynamic vibration absorber. Engineering, London, 174-769, 1952.

[6] K.C. Falcon, B.J. Stone, W.D. Simcock, C. Andrew, Optimization of vibration absorbers: a graphical method for use on idealized systems with restricted damping, Journal Mechanical Engineering Science, 9, 374381, 1967.

[7] G.B. Warburton, Optimum absorber parameters for various combination of response and excitation parameters, Earthquake Engineering and Structural Dynamics, 10, 381401, 1982.

[8] F. Sadek, B. Mohraz, A.W. Taylor, R.M. Chung, A method of estimating the parameters of tuned mass dampers for seismic applications, Earthquake Engineering and Structural Dynamics, 26, 617635, 1997.

[9] M.N.S. Hadi, Y. Arfiadi, Optimum design of absorber for MDOF structures, Journal of Structural Engineering-ASCE, 124, 12721280, 1998.

[10] G.C. Marano, R. Greco, B. Chiaia, A comparison between different optimization criteria for tuned mass dampers design, Journal of Sound and Vibration, 329, 4880-4890, 2010 .

[11] S. Pourzeynali, S. Salimi, H.E. Kalesar, Robust multi-objective optimization design of TMD control device to reduce tall building responses against earthquake excitations using genetic algorithms, Scentia Iranica, 20, 2, 207-221, 2013.

[12] N.B. Desu, S.K. Deb, A. Dutta, Coupled tuned mass dampers for control of coupled vibrations in asymmetric buildings, Structural Control and Health Monitoring, 13, 897916, 2006. 
[13] J.F. Jiménez-Alonso, A. Sáez, Robust optimum design of tuned mass dampers to mitigate pedestrian-induced vibrations using multi-objective genetic algorithms, Structural Engineering International, 27(4), 492-501, 2017.

[14] A.Y.T. Leung, H. Zhang, C.C. Cheng, Y.Y. Lee, Particle swarm optimization of TMD by non-stationary base excitation during earthquake, Earthquake Engineering and Structural Dynamics, 37, 1223-1246, 2008.

[15] A.Y.T. Leung, H. Zhang, Particle swarm optimization of tuned mass dampers, Engineering Structures, 31, 715-728, 2009.

[16] M. Fahimi-Farzam, B. Alinejad, Optimum design of tuned mass damper under base excitation using metaheuristic algorithm, $16^{\text {th }}$ European Conference on Earthquake Engineering, Thessaloniki, Greece, June 18-21, 2018.

[17] S.M. Nigdeli, G. Bekdaş, Optimum tuned mass damper design in frequency domain for structures, KSCE Journal of Civil Engineering, 21, 3, 912-922, 2017.

[18] H.Y. Zhang, L.J. Zhang, Tuned mass damper system of high-rise intake towers optimized by improved harmony search algorithm, Engineering Structures, 138, 270-282, 2017.

[19] S.M. Nigdeli, G. Bekdaş, A. Aydın, Metaheuristic based optimization of tuned mass dampers on single degree of freedom structures subjected to near fault vibrations, International Conference on Engineering and Natural Sciences (ICENS 2017), Budapest, Hungary, May 3-7, 2017.

[20] G. Bekdaş, A.E. Kayabekir, S.M. Nigdeli, Y.C. Toklu, Tranfer function amplitude minimization for structures with tuned mass dampers considering soil-structure interaction, Soil Dynamics and Earthquake Engineering, 116, 552-562, 2019.

[21] A. Farshidianfar, S. Soheili, ABC optimization of TMD parameters for tall buildings with soil structure interaction, Interaction and Multiscale Mechanics, 6, 339-356, 2013.

[22] M. Khatibinia, H. Gholami, R. Kamgar, Optimal design of tuned mass dampers subjected to continuous stationary critical excitation, International Journal of Dynamics and Control, 6, 3, 1094-1104, 2018.

[23] S. Etedali, H. Rakhshani, Optimum design of tuned mass dampers using multi-objective cuckoo search for buildings under seismic excitations, Alexandria Engineering Journal, 57, 4, 3205-3218, 2018.

[24] G. Bekdaş, S.M. Nigdeli, X.S. Yang, A novel bat algorithm based optimum tuning of mass dampers for improving the seismic safety of structures, Engineering Structures, 159, 89-98, 2018.

[25] S.M. Nigdeli, G. Bekdaş, X.S. Yang, Optimum tuning of mass dampers by using a hybrid method using harmony search and flower pollination algorithm. In: Del Ser J. (eds) Harmony Search Algorithm. ICHSA 2017. Advances in Intelligent Systems and Computing, Vol. 514, Springer, Singapore, 222-231, 2017.

[26] S.M. Nigdeli, G. Bekdaş, Optimum design of multiple positioned tuned mass dampers for structures constrained with axial force capacity, The Structural Design of Tall and Special Buildings, 28, 5, e1593, 2019. 
[27] S.M. Nigdeli, G. Bekdaş, Teaching-learning-based optimization for estimating tuned mass damper parameters, $3^{\text {rd }}$ International Conference on Optimization Techniques in Engineering (OTENG '15), Rome, Italy, November 7-9, 2015.

[28] M. Yucel, G. Bekdaş, S.M. Nigdeli, S. Sevgen, Estimation of optimum tuned mass damper parameters via machine learning, Journal of Building Engineering, 26, 100847, 2019.

[29] Z.W. Geem, J.H. Kim, G.V. Loganathan, A new heuristic optimization algorithm: harmony search, Simulation, 76, 2, 60-68, 2001.

[30] FEMA P-695. Quantification of Building Seismic Performance Factors. Washington.

[31] The MathWorks Inc MATLAB R2010a. Natick, MA; USA, 2010. 